\title{
EDUCAÇÃo AMBIENTAL NOS ANOS INICIAIS DO ENSINO FUNDAMENTAL: ESTRATÉGIAS PARA SENSIBILIZAÇÃO DOS ALUNOS
}

ENVIRONMENTAL EDUCATION IN THE INITIAL YEARS OF FUNDAMENTAL EDUCATION: STRATEGIES FOR STUDENT AWARENESS

DOI: http://dx.doi.org/10.23926/RPD.2526-2149.2020.v5.n1.p360-373.id626

\section{Iara Késia Alves dos Santos}

Licenciatura em Ciências

Biológicas (IFCE)

Especialista em Educação

Ambiental (UFC)

iarag20.is@gmail.com

\section{Antonio Jarbas Barros de Moraes}

Mestre em Geografia (UVA) jarbasgeografia@hotmail.co $\mathrm{m}$
Resumo: $\mathrm{O}$ objetivo deste trabalho é promover entre os alunos do $2^{\circ}$ ano do ensino Fundamental I da EEIEF Aristides Floriano de Oliveira, no município de Acaraú do estado brasileiro do Ceará, uma sensibilização ambiental por meio de estratégias de forma interdisciplinar. Trata-se de um estudo de caso, no qual foram utilizadas metodologias de leitura e escrita em diferentes disciplinas com a temática ambiental, que estimulou a criticidade e a criatividade dos alunos. Com a conclusão das atividades, promoveuse uma socialização junto a outras turmas da escola para que os alunos mostrassem suas produções em forma de mural. Os resultados mostraram que as atividades realizadas sensibilizaram os alunos para mudanças expressivas de comportamento em relação ao meio ambiente, auxiliando de forma significativa na alfabetização.

Palavras-chave: Educação Ambiental. Alfabetização. Interdisciplinaridade. Sensibilização.

\begin{abstract}
The objective of this work is to promote among the students of the 2nd year of Elementary Education I of EEIEF Aristides Floriano de Oliveira, in the municipality of Acaraú-CE, an environmental awareness through strategies in an interdisciplinary way. This is a case study, in which reading and writing methodologies were used in different subjects with an environmental theme, which stimulated the students' criticality and creativity. With the completion of the activities, socialization was promoted with other classes of the school so that students could show their productions in the form of a mural. The results showed that the activities carried out sensitized students to expressive changes in behavior in relation to the environment, helping significantly in literacy.
\end{abstract}

Keywords: Environmental Education. Literacy. Interdisciplinarity. Awareness. 


\section{INTRODUÇÃO}

A temática ambiental, em muitas instituições de ensino, é abordada em disciplinas como Geografia e Biologia, quando na verdade, deveria ser trabalhada em muitas outras, afinal, ela não é exclusiva de uma área do saber. A matéria deve ser tratada de modo universal ou interdisciplinar na educação por sua amplitude discursiva e pela necessidade de promoção de uma responsabilidade ambiental.

O objetivo deste trabalho é promover entre os alunos do $2^{\circ}$ ano do ensino Fundamental I da EEIEF Aristides Floriano de Oliveira, localizada no município de Acaraú no estado brasileiro do Ceará, uma conscientização ambiental, sensibilizando-os em relação aos cuidados com o meio ambiente por meio de estratégias interdisciplinares.

Para tanto, iniciar-se-á conceituando educação ambiental, interdisciplinaridade e sensibilização, pois estes se constituem essenciais no desenvolvimento deste artigo.

Segundo Reigota (1998, p. 43-50) a Educação Ambiental (EA) “aponta para propostas pedagógicas centradas na conscientização, mudança de comportamento, desenvolvimento de competências, capacidade de avaliação e participação dos educandos". A EA oportuniza não só a mudança de princípios como também o aumento de conhecimentos e desenvolvimentos de habilidades.

Fazenda (2003) define interdisciplinaridade como uma categoria de ação, que não significa a conexão entre os conteúdos de diferentes disciplinas, mas se constitui em um diálogo entre indivíduos, que somente depois, concretiza-se na inter-relação entre as disciplinas do currículo escolar visando um processo interno de construção do conhecimento. A EA é uma prática interdisciplinar que estabelece uma nova forma de desenvolver os conteúdos das disciplinas, transformando-se em sensibilizações e, consequentemente, mudança de valores.

A sensibilização, de acordo com Moura (2004, p. 41), é um processo educativo que sensibiliza por meio de estratégias vinculadas a vivências, transcende a racionalidade, pois envolve sensações, intuição e sentimentos. Neste sentido, sensibilizar para a EA é construir uma relação educativa do educando com o meio ambiente. Trata-se dos resultados construídos na prática docente como esta que apresentamos no artigo.

Esse trabalho é um estudo de caso baseado em Eisenhardt (1989) e Yin (2009), que sugerem o uso de metodologias que envolvam variadas atividades voltadas para o contexto social do educando. Essa variação desperta o interesse para a interdisciplinaridade na temática ambiental, neste caso, entre as disciplinas de Língua Portuguesa (LP); Geografia; Ciências; Religião; Artes e Educação Física. Alguns dos recursos usados nas atividades foram mídias 
(vídeos, slides); dinâmicas de leituras; contação de histórias; aulas ao ar livre (nos entornos da escola); oficinas; rodas de conversas; produções escritas e artísticas. Cada atividade foi realizada de modo a sensibilizar os alunos sobre a temática ambiental e, ao mesmo tempo, auxiliar o processo de alfabetização.

Desde os primeiros anos escolares, as crianças devem receber instruções sobre o meio ambiente, pois nesta faixa etária apresentam facilidade na exploração dos conhecimentos. Por essa razão, a EA em escolas de Educação Infantil e Fundamental é preponderante, já que o aprendizado em educação ambiental desenvolvido nesta fase servirá de base para futuras intervenções em outros anos de ensino (SILVA; MESQUITA; SOUZA, 2015).

O ambiente escolar é um dos primeiros locais formais para a conscientização sustentável ou sensibilidade ambiental dos futuros cidadãos. A EA é introduzida de forma interdisciplinar nos conteúdos relacionando as intervenções indiscriminadas do ser humano na natureza e os seus efeitos catastróficos. Por isso, defendemos que a escola é o lugar primordial para a orientação do saber interdisciplinar em EA. Podem ser verificadas nas próximas seções algumas discussões aqui empreendidas.

\section{REFERENCIAL TEÓRICO}

\subsection{EDUCAÇÃO AMBIENTAL NOS ANOS INICIAIS}

Educação Ambiental (EA) constitui-se numa forma abrangente de educação, que se propõe atingir os cidadãos através de um processo participativo permanente que procura incutir uma consciência crítica sobre a problemática ambiental. Deve procurar favorecer e estimular possibilidades de se estabelecer coletivamente uma "nova aliança" (entre os seres humanos e a natureza) que possibilite às espécies biológicas (inclusive a humana) a sua convivência e sobrevivência com dignidade (REIGOTA, 2009). Objetivando a formação de uma sensibilização ambiental que leve a formação de pessoas preocupadas com o meio em que vivem.

Os debates acerca da EA levam em consideração a construção de uma consciência cidadã com adoção de comportamentos ambientalistas em respeito ao meio ambiente (PELICIONI, 1998). Assim, a EA inserida nas escolas passa ser a ponte para a essa conscientização. Silva, Mesquita e Souza (2015) reforçam ser preciso que a EA construa novas formas de pensar práticas interdisciplinares que reforcem a consciência ambiental na realidade escolar. 
Fazenda (1991) interpreta que as ações interdisciplinares, aqui voltadas para EA, devem contestar a fragmentação do conhecimento nas disciplinas escolares. A aproximação entre as disciplinas, que pode ser identificada nas práticas interdisciplinares, se deve a certo empenho intencional dos sujeitos que conduzem o ensino-aprendizagem.

A interdisciplinaridade é um grande desafio dos educadores que pretendem superar práticas fragmentadas de ensino. Trata-se da interação entre as disciplinas por meio de temas em comum. Ela se propõe a trabalhar com um tema gerador que deve captar uma totalidade, e não apenas aspectos isolados ou fragmentários do cotidiano escolar (PONTUSCHKA; PAGANELLI; CACETE, 2007).

No mesmo sentido, Coimbra (1985) compreende que a ação interdisciplinar reúne práticas ambientais nas intervenções escolares. Destaca também que o trabalho didáticopedagógico com a EA, em prol da sustentabilidade, possibilita construir diálogos diversificados e transversais entre áreas do conhecimento. A escola precisa criar projetos com objetivos de diminuição dos impactos na natureza pela ação antrópica.

Além disso, é necessário que promova compreensões abrangentes dos saberes extraclasse, possibilitando maior criticidade sobre o contexto vivido, pois é nele que os alunos veem conhecimento ambiental na sua concretude (BRASIL, 1997). Partindo disso, há a necessidade de que o professor se empenhe na formação de estudantes para que sejam capazes de refletir a respeito das suas ações e danos causados ao meio ambiente.

Para Medeiros et al. (2011), algumas instituições de ensino já estão conscientes de que precisam trabalhar a problemática ambiental. As iniciativas em torno da questão têm sido desenvolvidas onde já foi incorporada a temática do meio ambiente nos sistemas de ensino. Nessa perspectiva, o ofício docente contribui com uma formação sustentável discente contínua e adequada às mudanças em curso na sociedade, de modo que eles desenvolvam a autonomia crítico-reflexiva logo nos anos iniciais.

A EA é essencial em todos os níveis dos processos educativos, especialmente nos anos iniciais da escolarização, já que é mais fácil conscientizar as crianças sobre as questões ambientais do que os adultos (MEDEIROS et al., 2011). É nos anos iniciais de escolarização que as crianças vão criando sua própria personalidade e desenvolvendo os seus valores.

$\mathrm{Na}$ faixa etária dos 2 aos 14 anos de idade, as crianças podem ser preparadas para diagnosticar problemas atuais e propor possíveis soluções. Elas tendem a ser mais engajadas, tendo maior disponibilidade em participar de causas ambientais (SILVA; MESQUITA; SOUZA, 2015). A curiosidade das crianças é o ponto de partida para a construção de opiniões. 
É também o marco inicial para o professor empreender estratégias criativas que permitam aos alunos aguçarem a aprendizagem.

Ainda no âmbito da curiosidade, Tiriba e Profice (2019) destaca a natureza no bem-estar e na saúde infantil, e quando em contato com a natureza, entende que as crianças percebem e constroem vínculos com os ambientes, seres e processos da natureza. Um dos problemas que impedem esse contato é justamente resistência do corpo docente em tirar o aluno da sala de aula. Tal resistência, muitas vezes, está atrelada a questões administrativas, como por exemplo, o cumprimento de calendários docentes (preparação para provas internas e externas), falta de apoio para conduzir práticas fora da escola (transporte, alimentação e pessoas dispostas a auxiliar).

Defende-se que a aula fora da sala é possível graças ao esforço docente em detrimento das limitações. É por isso que o professor precisa buscar auxílios que lhe permitam desenvolver o tema educação ambiental com crianças, mostrando que a busca pelo conhecimento é permanente. Para tanto, é necessário planejar um contexto educativo, com atividades interdisciplinares desafiadoras e significativas.

\section{Metodologia}

\subsection{EDUCAÇ̃̃O AMBIENTAL E LEITURA}

A prática pedagógica do trabalho foi realizada em uma turma de $2^{\circ}$ ano de ensino fundamental, com um total de 16 alunos da EEIEF Aristides Floriano de Oliveira no município de Acaraú-CE (Figura 1). Acaraú é um município brasileiro do estado do Ceará situado na Mesorregião Noroeste, a 198 km em linha reta da capital Fortaleza (IBGE, 2016). 
Figura 1 - Mapa de localização da EEIEF Aristides Floriano de Oliveira no município de Acaraú-CE

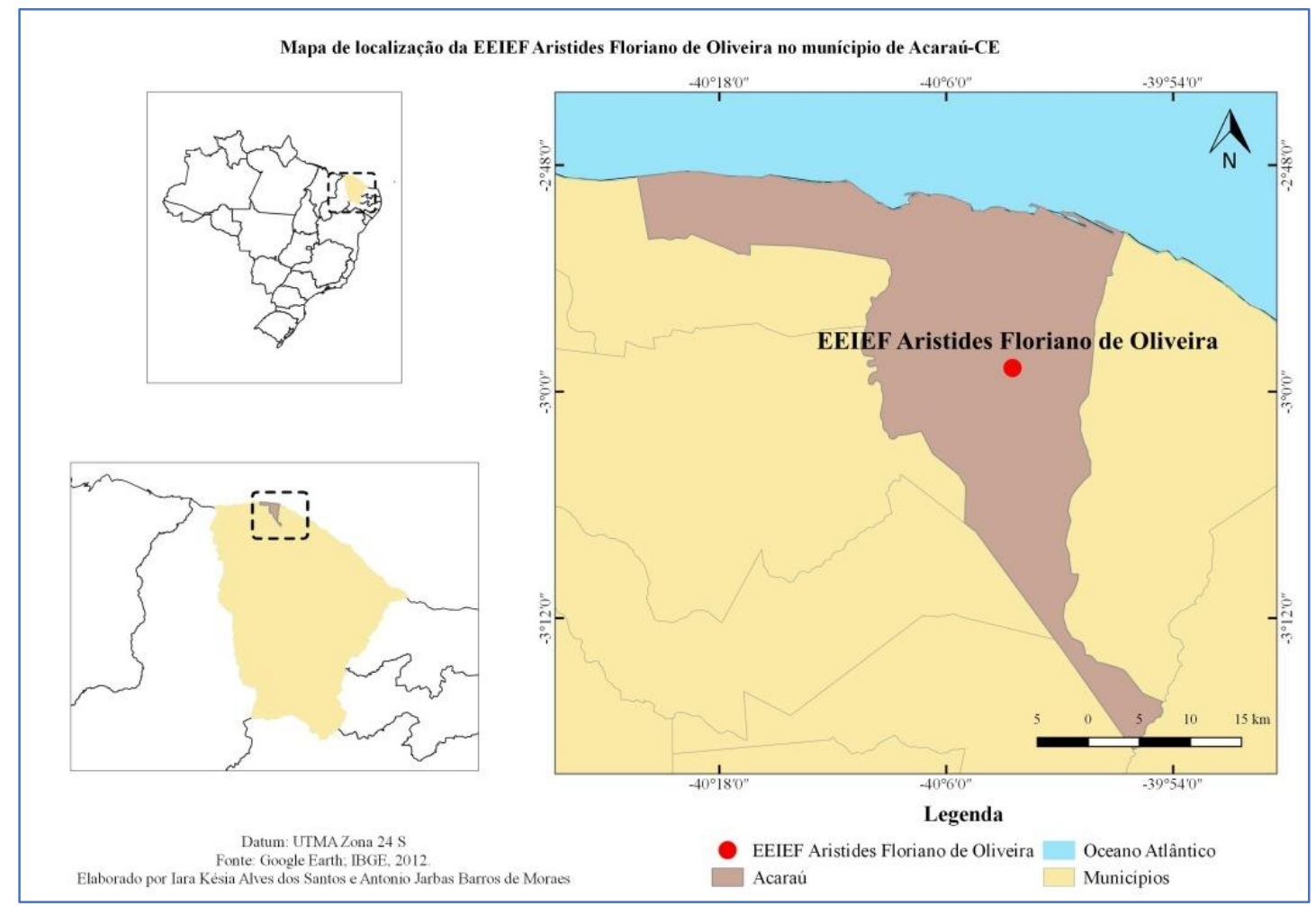

Fonte: Google Earth; IBGE, 2012. Elaborado por Iara Késia Alves dos Santos e Antonio Jarbas Barros de Moraes, 2020.

O presente trabalho é um estudo de caso com análises qualitativas a partir do material didático reunido na intervenção feita na escola referida anteriormente. Estamos de acordo com Eisenhardt (1989) e Yin (2009) quando refletem sobre o estudo de caso e afirmam que é um método de pesquisa detalhado por meio de práticas variadas, que tem como objetivo elucidar dinâmicas reveladas no contexto social dos sujeitos estudados. Para o estudo que apresentamos neste artigo, consideram-se as duas perspectivas, de variação dos recursos didáticos e da inclusão do contexto social dos educandos, que ajudaram nas intervenções interdisciplinares descritas nesta seção.

O trabalho englobou as disciplinas de Língua Portuguesa, Geografia, Ciências, Religião, Artes e Educação Física. Teve início no mês de maio, seguindo até o final do ano letivo de 2018. As seis disciplinas foram ministradas pela professora autora do artigo. Destaca-se que os espaços das aulas serviram para a execução da prática.

A interdisciplinaridade não acontece somente na referida polivalência. Ela acontece no coletivo docente da escola e na temática ambiental. O primeiro reúne, além da professora, a direção da escola, que autorizou o uso de materiais (tinta, folhas A4, dentre outros), as secretárias e auxiliares, que se disponibilizaram para a separação de livros relacionados com o 
meio ambiente, e a coordenação, ajudando em atividade quando fora de sala e na preparação de material. O segundo compreende a coletividade por meio da leitura.

Os recursos de interpretação textual, produção textual, imagens, pintura, roda de conversa e as aulas ao ar livre ajudaram a fomentar a aprendizagem da Educação Ambiental. Foram desenvolvidos nas referidas disciplinas.

O livro "O livre canto do sabiá”, de Claudenice Monteiro (2013), foi usado para leitura e interpretação. Foi confeccionada uma caixa de textos com ajuda das secretárias da escola para serem utilizadas posteriormente à leitura dos livros. Para a fabricação foram utilizados papelão, cola e EVA, contendo em seu interior textos e frases relacionadas à natureza. Os textos e as frases tinham como objetivo mostrar tanto problemas, como poluição, quanto recados de cuidados com o meio ambiente. Além da caixa de textos, usaram-se frases em cartazes criadas por nós, professores e alunos, com conotações sustentáveis, como por exemplo, "Salve o Planeta"; "O planeta em nossas mãos". A leitura acontecia individualmente e coletivamente, seguida de reflexões em grupo.

Também foram utilizados imagens e vídeos apresentados em multimídia para retratar a realidade ambiental dos alunos, ou seja, imagens de problemas ambientais que eles estão acostumados a ver no percurso de casa à escola, tais como lixo e queimadas. Para a captura das imagens foi necessário o uso de um celular, um computador para editar e slides para mostrar e debater.

$\mathrm{Na}$ produção textual e pintura, elaboraram-se pequenos textos, frases ou somente desenhos. Traduziu-se parte dos conhecimentos dos alunos, adquiridos ao longo da prática por meio de textos e pinturas. Foram utilizadas folhas A4, lápis de cores, canetas coloridas, giz de cera e lápis.

A roda de conversa era organizada após procedimentos de leitura e intepretação; e produção textual e pintura. A conversa mediada despertou o senso reflexivo dos alunos acerca da coletividade em prol de uma sociedade mais sustentável. Tais atividades possibilitaram junto aos alunos, não só o despertar para a sensibilidade e conscientização ambiental, como foram facilitadoras do seu processo de alfabetização, tendo em vista que alguns alunos não leitores tornaram-se leitores fluentes.

As práticas de leitura, produção textual e pinturas, realizadas em aulas ao ar livre, ajudaram a reforçar as abordagens acerca da EA. No pátio mostramos que é possível realizar ações cotidianas que ajudam o meio ambiente, tais como: fazer coleta seletiva de resíduos 
sólidos e não deixar a torneira pingando. Os alunos no pátio da escola fizeram as produções textuais, em cartazes e folhas A4, e as pinturas.

A culminância, que ocorreu na sala, reuniu professores, gestores e alunos de diferentes turmas para participarem da exposição, em forma de mural, das produções textuais e artísticas dos alunos do $2^{\circ}$ ano. $\mathrm{O}$ mural foi feito pelos alunos com ajuda da professora e da coordenação da escola, que disponibilizou o material.

\section{Resultados}

\subsection{UMA EXPERIÊNCIA INTERDISCIPLINAR EM EDUCAÇÃO AMBIENTAL}

A leitura, interpretação e participação coletiva foram o ponto chave para despertar nos alunos o interesse pela temática ambiental, como também auxiliou no processo de alfabetização da turma.

No momento da leitura do livro "O livre canto do sabiá" (MONTEIRO, 2013), alguns educandos compararam os textos com o contexto das suas vivências. As queimadas, exploração da fauna e flora são ações que estão presentes no dia a dia, inclusive, são muitas vezes meio de subsistência familiar. Entretanto, ainda que seja de forma reduzida se comparadas à realidade de grandes centros urbanos, agridem o meio ambiente.

A partir da leitura do referido livro, foram explorados em modo cartaz, textos com conotações sustentáveis. Os textos escolhidos, além de exercerem uma função social específica, ocorrendo em situações cotidianas de comunicação, traziam reflexões sobre o meio ambiente. O cartaz de campanha - Salve o Planeta - que fazia um convite para que ajudassem na preservação do meio ambiente, o Texto informativo - O planeta em nossas mãos - que auxiliou para a reflexão sobre a educação ambiental e reforçou que cada um precisa fazer sua parte, pois é na coletividade que os problemas ambientais podem ser sanados.

O material didático escolhido para a aula, livros e outros, mostrou o quão relevante é cuidar da natureza e que são as pequenas atitudes do dia a dia que fazem a diferença. As discussões realizadas refletiram diretamente no comportamento dos alunos, que passaram a cuidar da sua sala de aula, mantendo-a limpa, evitando o desperdício de água nos bebedouros e demonstrando um cuidado com os animais que vivem nos arredores da escola. Sampaio (2007, p. 16) reforça esse pensamento ao afirmar que "a força da natureza sensibilizava cada uma das crianças de acordo com sua personalidade, sua percepção de mundo e sua curiosidade". A curiosidade dos alunos ajudou a capturar, nos recursos didáticos apresentados, informações que permitiram a realização de análises e debates em sala de aula. Buscou-se a compreensão 
socioambiental das ações humanas mediante a natureza, tendo como fim o aporte para reflexões sobre as práticas cotidianas dos alunos.

As leituras e interpretações renderam boas discussões e, para melhorar o debate, propomos aos alunos produções textuais sobre a temática estudada. Também sugerimos que pedissem opiniões de outros sujeitos da escola (outros alunos, professores, secretárias, diretor e coordenadores). O objetivo era possibilitar uma análise discente que contribuísse para uma revisão do conteúdo proposto. Então escreveram frases curtas e fizeram ilustrações que podem ser conferidas a seguir (Figura 2, 3 e 4).

Figura 2 - Frases produzidas pelos alunos do $2^{\circ}$ ano. A e B - Produção de frases sobre o planeta desejado pelos alunos do $2^{\circ}$ ano

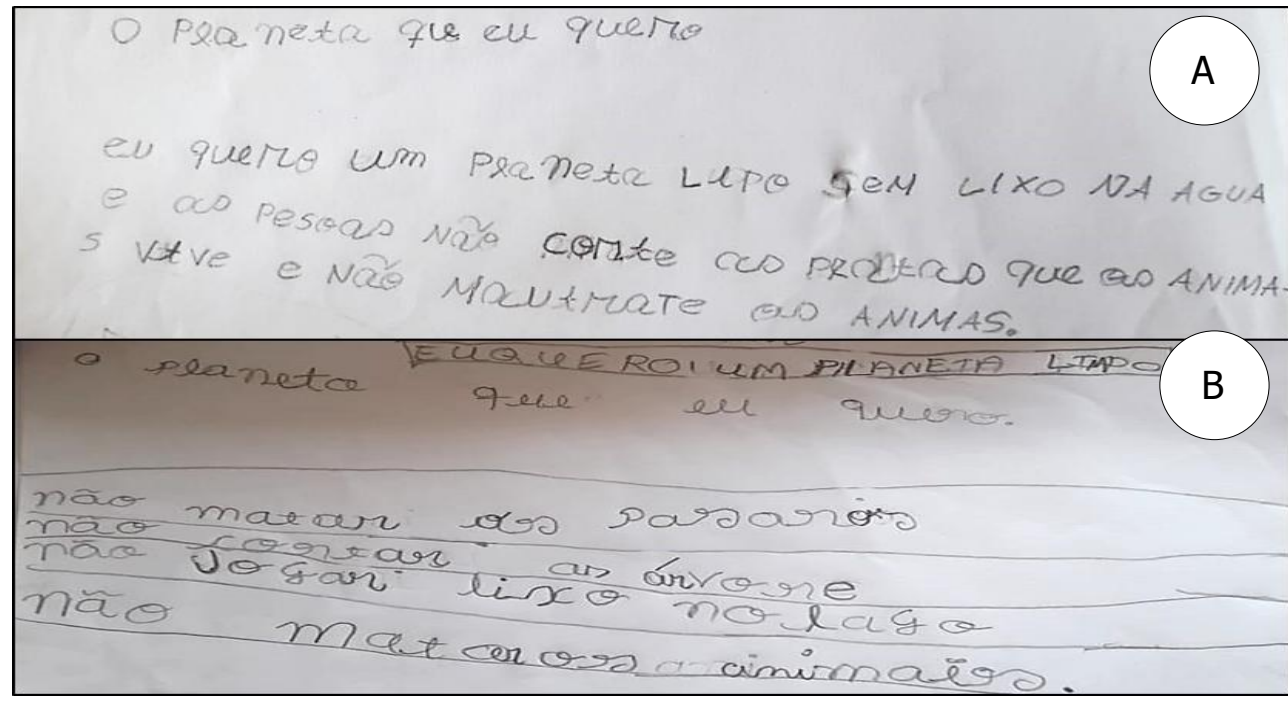

Fonte: Santos, 2018.

Figura 3 - Produções de arte sobre meio ambiente feita pelos alunos do $2^{\circ}$ ano. A, B, C, D - As produções demonstram o planeta e ambiente desejado pelos alunos, com o equilíbrio entre a fauna e a flora

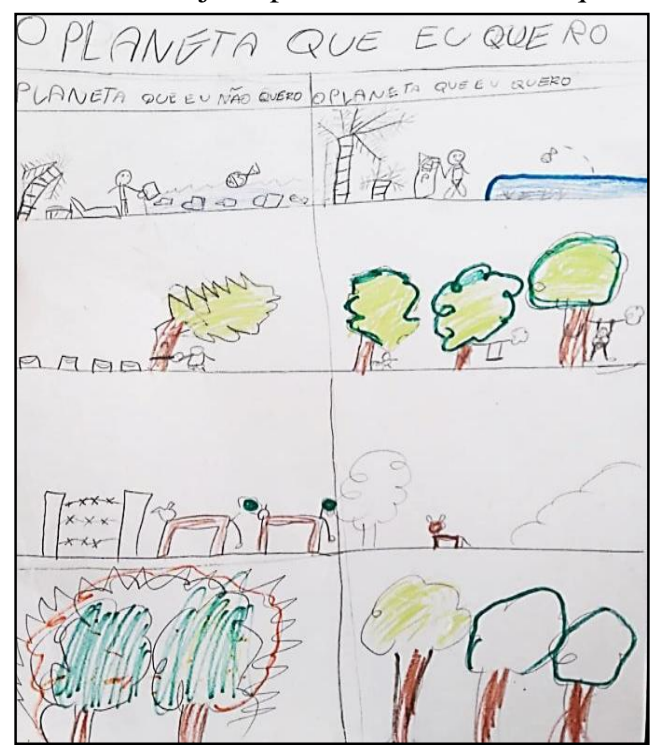

Fonte: Santos, 2018. 
Figura 4 - Produção artística de uma aluna do $2^{\circ}$ ano, demonstrando o planeta que deseja e o que não deseja

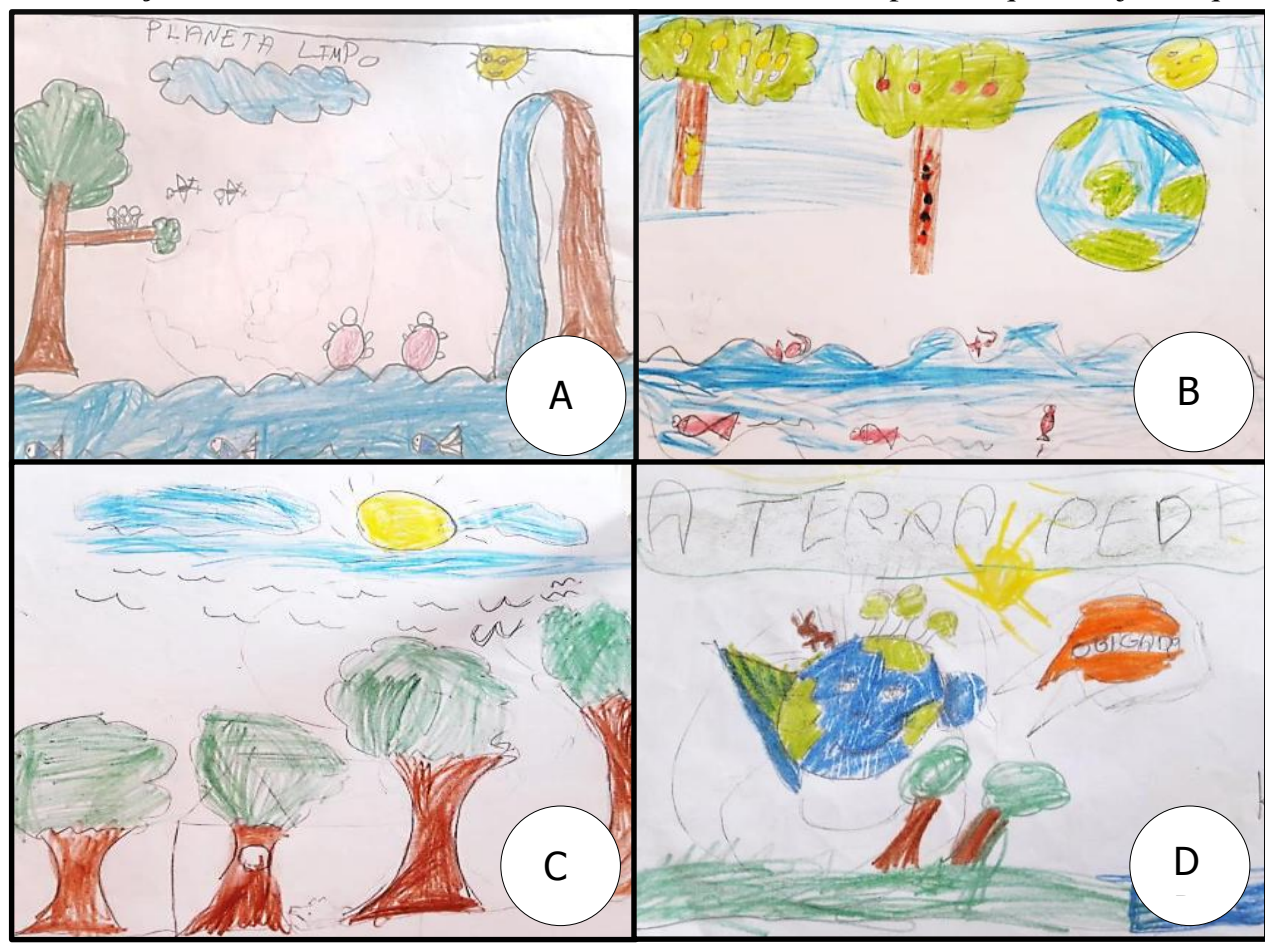

Fonte: Santos, 2018.

De acordo com as produções de textos das crianças é possível observar sua preocupação com as plantas e os animais. Um dos pontos ressaltados no decorrer do trabalho se trata do entendimento acerca do valor ambiental que os animais têm na natureza. Na figura 4 é possível observar que a aluna almeja um ambiente onde as pessoas possam estar em sintonia com a natureza, respeitando o meio ambiente, como também apresenta o pedido para não poluir os rios, não cortar as árvores, diminuir a criação de gado para a consequente diminuição do gás metano e as queimadas. As imagens e os relatos dos alunos reivindicam intervenções coletivas, como essa que aconteceu na escola, para se converter em um planeta verde e com menos poluição.

A produção de texto é preponderante para que o aluno consiga expressar, por meio da escrita, o seu saber. E a produção artística, especialmente o desenho, aparece na Educação Ambiental como uma alternativa de registro de observações do meio natural e da sociedade, ajudando na interpretação e compreensão do mundo pelo indivíduo, principalmente se é baseado na observação, podendo se adequar a várias atividades e em diferentes momentos do processo educativo (ROSA; BIANCO, 2004).

As rodas de conversas e aulas ao ar livre que foram realizadas serviram de estímulo para o educando complementar as discussões feitas em sala. Exerceram papeis fundamentais para que as crianças pudessem expressar suas opiniões e vivências. Estas foram válidas nas 
mudanças de atitudes dos discentes. Diante disso, observou-se que os reflexos da prática reverteram-se em atitudes sustentáveis nos mais variados ambientes de atuação do aluno, como por exemplo, em sua casa, escola, rua, dentre outros.

As atividades desenvolvidas (Figura 5) contribuíram para a superação das práticas rotineiras na escola, que geralmente se constitui na explicação do conteúdo pelo professor e o aluno é apenas aprendiz passivo. O aluno, o professor e outros sujeitos da escola, nesta perspectiva empreendida no artigo, são atuantes no processo de ensino-aprendizagem.

Figura 5 - Imagens das atividades desenvolvidas. A- Dinâmica de separação de lixo, B- Produção escrita, CRoda de leitura com caixa de textos, D- Vídeos educativos, E- Leitura, F- Germinação com o conto João e o Pé de feijão

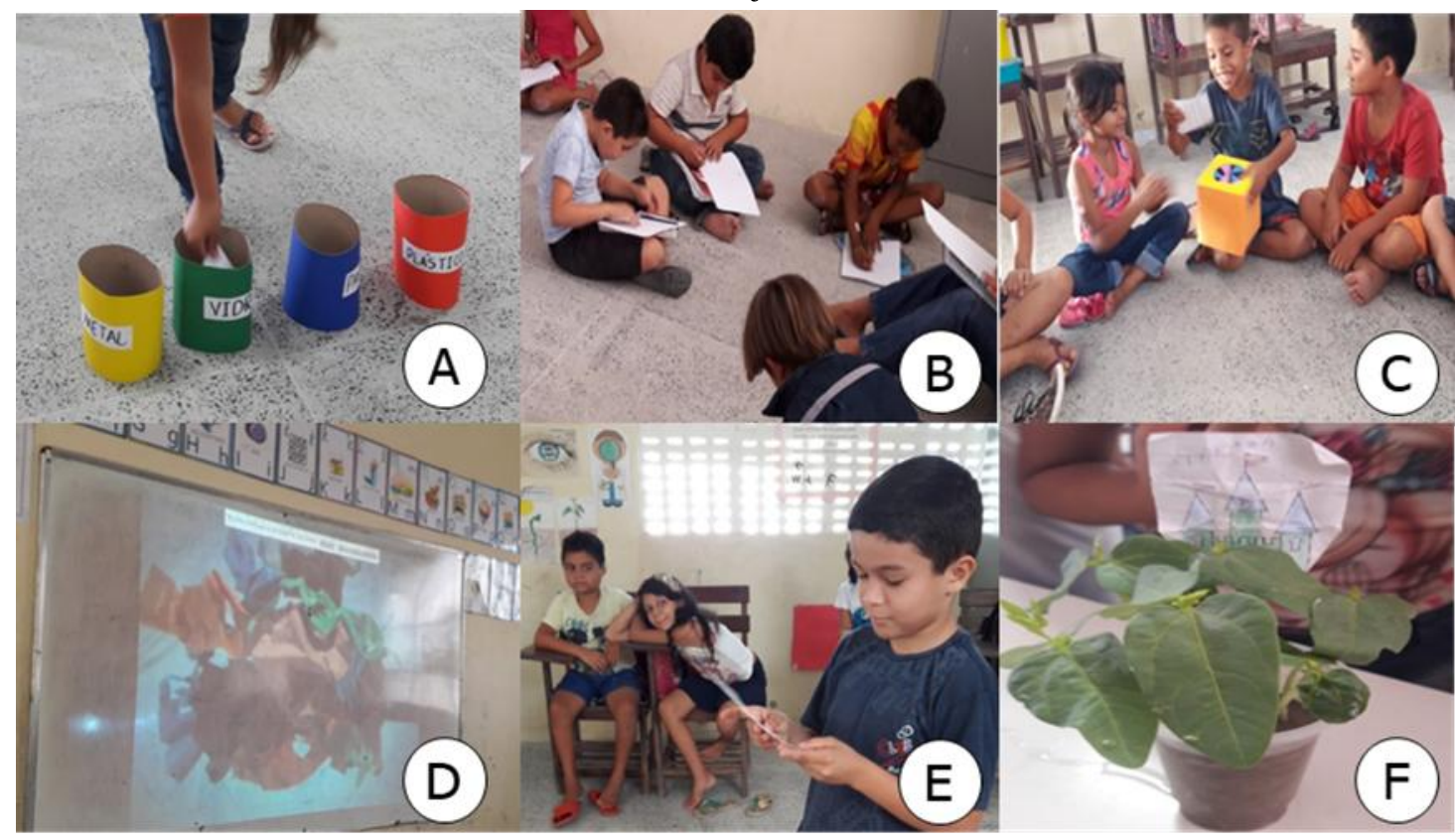

Fonte: Santos, 2018.

Como resultado do trabalho, algumas das produções escritas e artísticas foram utilizadas para a construção de um mural que, depois de construído, foi exposto na escola pelos alunos da turma. Assim, os estudantes compartilharam seu aprendizado com os professores, gestores e demais alunos da escola. Vale ressaltar que não foi possível registrar este último momento devido à falta de recurso fotográfico no dia da culminância.

Portanto, a interdisciplinaridade pode ser ressignificadora do estudo em Educação Ambiental, levando o aluno a ler, observar, refletir e questionar sobre o processo de efetivação da sustentabilidade na sociedade. Entretanto, deve-se enfatizar que práticas interdisciplinares, por si mesmas, não têm a capacidade de garantir a aprendizagem. Porém, neste caso, despertaram o aluno para a leitura e o conhecimento sustentável. 
Destaca-se a importância do desenvolvimento desse trabalho simultaneamente entre as disciplinas de Língua Portuguesa (LP); Geografia; Ciências; Religião; Artes e Educação Física, pois em cada uma delas foram promovidas ações com um objetivo em comum, a sensibilização dos alunos dos anos iniciais do ensino fundamental. Para tanto, o uso da leitura e produções textuais em todas as disciplinas, principalmente na LP, os textos, oficinas e recursos digitais nas disciplinas de Geografia e Ciências, as produções de desenhos na disciplina de Artes e na disciplina de Educação Física, de forma interdisciplinar, foram caras para se objetivar o presente trabalho.

\section{CONSIDERAÇÕES FINAIS}

Os resultados mostram que as atividades que foram desenvolvidas sensibilizaram os alunos, resultado perceptível principalmente pela mudança de atitude observada no decorrer do processo, dentre estas se podem citar a preocupação com os animais, os cuidados para manter a escola limpa, jogando o lixo no local apropriado, e o cuidado para evitar desperdício de água na escola. Além das mudanças expressivas de comportamento em relação à natureza, esse trabalho auxiliou de forma significativa o processo de alfabetização dos estudantes.

Constatou-se que o uso de metodologias interdisciplinares no ensino da EA chama a atenção dos educandos, facilitando o processo de ensino-aprendizagem, auxiliando na construção de mudanças de atitudes, valores e pensamentos nas crianças, contribuindo para a formação de cidadãos críticos e conscientes, respeitando a vida.

Ressaltamos a importância da educação para a construção de uma sociedade melhor. Por isso, ações de Educação Ambiental em escolas de ensino fundamental são essenciais. Esse estudo contribuiu com a reflexão sobre educação ambiental na turma do $2^{\circ}$ ano, como também foi fundamental para o letramento, à medida que os alunos produziram, leram, debateram e vivenciaram a EA.

Portanto, as adversidades estruturais e sociais que o professor enfrenta em sua práxis podem servir de mote para suas intervenções. Trata-se da busca por meios para superar problemas como o desinteresse discente e a fragilidade da infraestrutura da escola, ou seja, práticas que se desvencilhem do comodismo e das rotinas. Com isso, acreditamos na possibilidade de aprimorar as aulas de Educação Ambiental com intervenções que reúnam a leitura, a criatividade e a criticidade acerca do meio ambiente. 


\section{REFERÊNCIAS}

COIMBRA, José de Avila Aguiar. O outro lado do meio ambiente. São Paulo, CETESB/ASCETESB, 1985.

BRASIL. Secretaria de Educação Fundamental. Parâmetros curriculares nacionais: apresentação dos temas transversais (ética). Brasília: MEC/SEF, 1997.

EISENHARDT, Kathleen M. Building theories form case study research. Academy of Management Review. New York, New York, v. 14 n. 4. 1989. Disponível em:

https://edisciplinas.usp.br/pluginfile.php/4310941/mod_resource/content/1/1.Eisenhardt1989BuildingTheoriesFromCSR.pdf. Acesso em: 15 abr. 2020.

FAZENDA, Ivani Catarina Arantes. Interdisciplinaridade: qual o sentido. São Paulo: Paulus, 2003.

FAZENDA, Ivani Catarina Arantes (org.). Práticas interdisciplinares na escola. São Paulo: Cortez, 1991.

IBGE, Instituto Brasileiro de Geografia e Estatística. Cidades 2016. Site do Instituto Brasileiro de Geografia e Estatística. Disponível em:

http://www.cidades.ibge.gov.br/v3/cidades/municipio/2304657. Acesso em: 08 set. 2016.

MEDEIROS, Aurélia Barbosa et al. A Importância da educação ambiental na escola nas séries iniciais. Revista Faculdade Montes Belos, v. 4, n. 1, set. 2011.

MONTEIRO, Claudenice Brito. O livre canto do sabiá. Ilustrações de Mariza Angélica Brito. Fortaleza: SEDUC, 2013.

MOURA, Ana Carolina de Oliveira Salgueiro de. Sensibilização: diferentes olhares na busca dos significados. Dissertação (Mestrado em Mestrado Em Educação Ambiental) -

Universidade Federal do Rio Grande, 2004.

PELICIONI, Maria Cecília Focesi. Educação ambiental, qualidade de vida e sustentabilidade. Saúde e sociedade, São Paulo, v.7, n.2, p.19-31, 1998.

PONTUSCHKA, Nidia Nacib; PAGANELLI, Tomoko Iyda; CACETE, Núria Hanglei. Para Ensinar e Aprender Geografia. São Paulo: Ed. Cortez, 2007.

REIGOTA, Marcos. O que é Educação Ambiental. Coleção Primeiros passos. São Paulo: Brasiliense, 2009.

REIGOTA, Marcos. Desafios à educação ambiental escolar. In: JACOBI, P. et al. (orgs.). Educação, meio ambiente e cidadania: reflexões e experiências. São Paulo: SMA, 1998. p.43-50.

ROSA, Antônio Carlos Machado; BIANCO, Saul. Hortas Escolares: o ambiente horta escolar como espaço de aprendizagem no contexto do Ensino Fundamental. Programa Hortas Escolares. Florianópolis: Instituto Souza Cruz, 2004. 
SAMPAIO, Rosa Maria Whitaker. Freinet: evolução histórica e atualidades. 2. ed. São Paulo: Scipione, 2007.

SILVA, Aline Cândida; MESQUITA, Glaucia Machado; SOUZA, Marcos Aurélio Pessoa. Educação ambiental como paradigma para a construção da sustentabilidade. Revista REGET, Santa Maria, v. 19, n.2, 2015.

TIRIBA, Léa; PROFICE, Christiana Cabicieri . Crianças da Natureza: vivências, saberes e pertencimento. Educação e Realidade. Edição eletrônica , v. 44, p. 1, 2019. Disponível em: http://www.scielo.br/scielo.php?script=sci_arttext\&pid=S2175-62362019000200408. Acesso em: 16 abr. 2020.

YIN, Robert .K. Case study research, design and methods (applied social research methods). Thousand Oaks. California: Sage Publications, 2009.

Recebido em: 24 de fevereiro de 2020 . Aprovado em: 22 de abril de 2020. 